\title{
Water and carbon dioxide distribution in the 67P/Churyumov-Gerasimenko coma from VIRTIS-M infrared observations
}

\author{
A. Migliorini ${ }^{1}$, G. Piccioni ${ }^{1}$, F. Capaccioni ${ }^{1}$, G. Filacchione ${ }^{1}$, D. Bockelée-Morvan ${ }^{2}$, S. Erard $^{2}$, C. Leyrat $^{2}$, \\ M. R. Combi ${ }^{3}$, N. Fougere ${ }^{3}$, J. Crovisier ${ }^{2}$, F. W. Taylor ${ }^{4}$, M. C. De Sanctis ${ }^{1}$, M. T. Capria ${ }^{1}$, D. Grassi ${ }^{1}$, G. Rinaldi ${ }^{1}$, \\ G. P. Tozzi ${ }^{5}$, and U. Fink ${ }^{6}$ \\ ${ }^{1}$ Istituto di Astrofisica e Planetologia Spaziali - INAF, via Fosso del Cavaliere, 100, 00133 Rome, Italy \\ e-mail: alessandra.migliorini@iaps.inaf.it \\ ${ }^{2}$ LESIA/Observatoire de Paris/CNRS/UPMC/Université Paris-Diderot, 75013 Meudon, France \\ 3 Space Physics Research Laboratory, University of Michigan, Ann Arbor, MI 48109, USA \\ ${ }^{4}$ Department of Physics, Oxford University, Oxford OX1 3PU, UK \\ 5 INAF, Observatorio Astrofisico di Arcetri, Largo E. Fermi 5, 50125 Firenze, Italy \\ ${ }^{6}$ Lunar and Planetary Laboratory, University of Arizona, Tucson, AZ 85721, USA
}

Received 29 October 2015 / Accepted 12 February 2016

\section{ABSTRACT}

\begin{abstract}
Context. Studying the coma environment of comet 67P/Churyumov-Gerasimenko (67P) is one of the primary scientific goals of the VIRTIS experiment on the ESA Rosetta mission.

Aims. The distribution and variability of water vapour and carbon dioxide in the comet's coma are needed to estimate their production rate, abundances in the nucleus, and the spatial distribution of the active regions.

Methods. Infrared emission lines from vibrational bands of water and carbon dioxide at 2.67 and $4.27 \mu \mathrm{m}$, respectively, were observed by the VIRTIS-M imaging channel and mapped from close to the nucleus up to $\sim 10 \mathrm{~km}$ altitude with a resolution of $\sim 40 \mathrm{~m} / \mathrm{px}$. A dataset consisting of 74 observations in the $1-5 \mu \mathrm{m}$ spectral range acquired from 8 to 14 April 2015 when $67 \mathrm{P}$ was at a heliocentric distance of $1.9 \mathrm{AU}$ is analysed in this work. A statistical correlation between the gas distribution and the surface's active regions was performed.

Results. The maximum $\mathrm{H}_{2} \mathrm{O}$ emission is observed within $3 \mathrm{~km}$ from the nucleus and is mainly concentrated above two active regions, Aten-Babi and Seth-Hapi, while the $\mathrm{CO}_{2}$ distribution appears more uniform with significant emissions coming from both the "head" and southern latitude regions. In the equatorial region, the column densities of both species decrease with altitude, although $\mathrm{CO}_{2}$ decreases more rapidly than $\mathrm{H}_{2} \mathrm{O}$. The calculated $\mathrm{CO}_{2} / \mathrm{H}_{2} \mathrm{O}$ column density ratios above Aten-Babi and Seth-Hapi are $2.4 \pm 0.6 \%$ and $3.0 \pm 0.7 \%$, respectively. A value equal to $3.9 \pm 1.0 \%$ is observed at equatorial latitudes in the region encompassing Imothep. Conclusions. VIRTIS-M has mapped the distribution of water vapour and carbon dioxide around the nucleus of 67P with unprecedented spatial resolution. The different water and carbon dioxide outgassing above the surface, seen in the VIRTIS-M data, might be indicative of a different thermal history of the northern and southern hemispheres of 67P.
\end{abstract}

Key words. comets: individual: $67 \mathrm{P} / \mathrm{CG}$ - techniques: imaging spectroscopy

\section{Introduction}

So far, only a few inner cometary comae have been investigated in detail by dedicated space missions. Vega (Sagdeev et al. 1986) and Giotto (Reinhard 1986) observed comet 1P/Halley, followed by Deep Space 1 to 19P/Borrelly (Soderblom et al. 2002), the Deep Impact comet 9P/Tempel 1 in July 2004 (Feaga et al. 2007), and the EPOXI comet 103P/Hartley 2 (A'Hearn et al. 2011). In addition, the Stardust mission (Brownlee et al. 2006) collected samples from comet 81P/Wild 2, which were eventually studied in laboratories on the ground and which later flew by and imaged regions of 9P/Tempel 1 not seen by Deep Impact including the impactor site itself (Thomas et al. 2013).

The Rosetta spacecraft was launched in March 2004, and after a ten-year long journey approached the comet 67P/Churyumov-Gerasimenko (67P) in August 2014 at a heliocentric distance of 3.59 AU (Astronomical Units). In this approaching phase, the spacecraft investigated the comet's surface to identify the best site to deliver the Philae lander. The landing occurred on 12 November 2014, while the orbiter and its experiments continued the surface and coma monitoring. Remote sensing observations also investigate the inner coma, which is not resolved from the ground.

Comets are mainly composed of ices, such as water and carbon dioxide, which sublimate when the body approaches the Sun. The study of the coma's chemical content provides information on its composition, and it also gives insight into the gaseous species distribution on the comets' surfaces and sub-surfaces. First identifications of water and carbon dioxide species in comet Halley were performed with the IKSVega experiment during its close encounter with the comet on March 1986 (Combes et al. 1988). The $\mathrm{H}_{2} \mathrm{O}$ and $\mathrm{CO}_{2}$ production rates, inferred during the Vega 1 flyby, were $\sim 10^{30} \mathrm{~s}^{-1}$ and $\approx 2.7 \times 10^{28} \mathrm{~s}^{-1}$, respectively. Weaker emission features due to $\mathrm{H}_{2} \mathrm{CO}$ and $\mathrm{CO}$ were also possibly identified in the infrared spectral region, as well as hydrocarbons and organics. More recently, the water emission has been investigated in detail in the ambient inner coma of comet 9P/Tempel 1 (Feaga et al. 2007) before the impact, and distribution maps around the nucleus were provided. They show that water tends to sublimate when illuminated by the 
Sun, while carbon dioxide emission, detected at the same time, does not share the same behaviour. The surface of the nucleus of 67P appears uniformly coated by dark, dehydrated, refractory, and organic-rich material (Capaccioni et al. 2015b).

Infrared observations of the coma of $67 \mathrm{P}$ during the approaching phase of the mission are discussed in BockeléeMorvan et al. $(2015,2014)$. The authors presented water and carbon dioxide emissions detected by the high-resolution channel of the Visible, Infrared and Thermal Imaging Spectrometer (VIRTIS) onboard Rosetta. The inferred water production rate ranges between $6.1 \times 10^{25}$ and $1.0 \times 10^{26} \mathrm{~s}^{-1}$ during the $12-\mathrm{h}$ nucleus rotation period. Water emission appeared concentrated above the neck regions, which leads us to believe that these are the most productive sources for water. In contrast, $\mathrm{CO}_{2}$ escapes from both illuminated and non-illuminated regions above the nucleus, which is also consistent with the findings for comet 9P/Tempel 1 (Feaga et al. 2007). The $\mathrm{CO}_{2}$ to $\mathrm{H}_{2} \mathrm{O}$ column density ratio varies from $2 \%$ to $30 \%$, depending on the illumination of the regions considered.

Observations with Rosetta Orbiter Spectrometer for Ion and Neutral Analysis (ROSINA) during August-September 2014, at a heliocentric distance of about 3.5 AU, allowed identification of compositional differences in the coma correlated with comet's surface (Hässig et al. 2015). The water sublimation is higher at positive latitude regions, corresponding to the summer hemisphere at the time of observations, while a broad region where $\mathrm{CO}_{2}$ emission is intense is located at negative latitudes, which are associated to the winter hemisphere. The same differences between the relative abundances of $\mathrm{H}_{2} \mathrm{O}$ and $\mathrm{CO}_{2}$ between the summer and winter hemispheres were observed by ROSINA at a heliocentric distance of 3.15 AU (Le Roy et al. 2015). The authors report a $\mathrm{CO}_{2}$ abundance value varying between $2.5 \%$ and $80 \%$ relative to water. The variability is linked to seasonal effects. In the millimetre and submillimetre ranges, the $1(1,0)-1(0,1)$ transitions of the $\mathrm{H}_{2}^{16} \mathrm{O}$ and $\mathrm{H}_{2}^{18} \mathrm{O}$ lines are detected by the Microwave Instrument on the Rosetta Orbiter (MIRO), as reported in Gulkis et al. (2015) and Biver et al. (2015). The water production rate, estimated during the approaching phase in July 2014 (Gulkis et al. 2015) and in September 2014 (Biver et al. 2015), is of the order of $4 \times 10^{25}$ molecules $/ \mathrm{s}$, at a heliocentric distance from 3.6 AU to 3.41 AU. In the analysed data, the highest column density is observed in the neck to subsolar regions, although very low outgassing or possibly backflow is also observed on the nightside.

Some preliminary results were shown in Capaccioni et al. (2015a), for VIRTIS-M data acquired in December 2014. The asymmetric distribution of $\mathrm{H}_{2} \mathrm{O}$ and $\mathrm{CO}_{2}$, detected in the analysed spectra, was evident, but no quantitative estimation of column densities was reported.

In the present paper we discuss data acquired by the mapping channel of VIRTIS onboard Rosetta from 8 to 14 April 2015, when the comet was at a heliocentric distance of 1.9 AU. In Sect. 2 data selection and processing are described. Results are presented in Sect. 3 for the identified species; they are discussed in terms of spatial distribution, in relation to the comet's surface (Sect. 4). Conclusions and perspectives are provided in Sect. 5 .

\section{Observations and column densities derivations}

\subsection{VIRTIS-M description}

The Visible and InfraRed Thermal Imaging Spectrometer (VIRTIS) is composed of two channels (Coradini et al. 2007): VIRTIS-M has a $3.6^{\circ}$ wide field of view and is able to simultaneously acquire two-dimensional spatial-spectral frames in the $0.27-5.1 \mu \mathrm{m}$ range. VIRTIS-H is a cross-dispersed spectrometer, operating in the $2-5 \mu \mathrm{m}$ spectral range. Its spectral resolving power ranges between 1300 and 3000 within each spectral order. In the following, a detailed description of the mapping channel of VIRTIS is provided.

A Shafer telescope $(D=47.5 \mathrm{~mm}, f / 3.2)$, equipped with a primary scanning mirror, is used to collect and focus light on the Offner spectrometer's slit. A dual zone, convex reflectance grating is used as a dispersive element, able to split VIS $(0.25-1 \mu \mathrm{m})$ and IR $(1-5 \mu \mathrm{m})$ beams onto two different $256 \times 432$ (sample $\times$ bands) focal plane arrays, a CCD and a $\mathrm{HgCdTe}$ array, respectively. The resulting field of view (FOV) is equal to $3.6^{\circ}$ with an instantaneous field of view (IFOV) of $250 \mu \mathrm{rad}$. The spectral sampling is of about 2 and $10 \mathrm{~nm}$ per spectral channel for the VIS and IR channels, respectively. The instrument can operate in both scan and pushbroom modes depending on the spacecraft distance and velocity with respect to the target by moving or maintaining at fixed position the internal scan mirror, respectively. A single acquisition contains both spatial information along the sample axis (i.e., along the slit) of the detectors and spectral information along the band axis. A hyperspectral data cube is built by repeating successive acquisitions in time along the third spatial axis (lines) by either scan mirror or relative spacecraft pointing motion.

The two VIRTIS-M focal planes are equipped with ordersorting filters to reduce contaminations due to higher spectral orders coming from the diffraction grating. The two filters placed on the visible channel's detector have a junction at $0.640-0.651 \mu \mathrm{m}$; the five filters on the infrared channel detector have four junctions at $1.415-1.576 \mu \mathrm{m}, 2.388-2.548 \mu \mathrm{m}$, 3.671-3.765 $\mu \mathrm{m}$, and 4.284-4.397 $\mu \mathrm{m}$ (Coradini et al. 2007). In general, the spectral radiance measured through the junctions has been corrected by the calibration pipeline. However, despite this correction some residual signals remain present. The spectral regions at $2.388-2.548 \mu \mathrm{m}$ and $4.284-4.397 \mu \mathrm{m}$, which are those including a filter junction close to the $\mathrm{H}_{2} \mathrm{O}$ and $\mathrm{CO}_{2}$ emissions respectively, have not been included in the analysis.

Both focal planes and the optical module containing the telescope and the spectrometer are maintained at cryogenic temperatures thanks to an active cooler and passive radiators in order to reduce detectors' dark current and internal background emission: this is particularly important for achieving a good signal-to-noise ratio in the thermal spectral region, e.g. between 4 and $5 \mu \mathrm{m}$. The instrument periodically measures internal background and dark current by closing an internal shutter, placed at the spectrometer's slit, and automatically subtracts it from the science data before transmitting data on ground. Once on the ground, the raw data are converted in spectral radiance by applying the calibration pipeline (Filacchione 2006; Ammannito et al. 2006; Filacchione et al. 2006) and additional corrections derived from in-fight data (Migliorini et al. 2013; Raponi 2014).

\subsection{Selected dataset}

In Table A.1 we list the 74 observations acquired by the IR channel (1-5 $\mu \mathrm{m})$ of VIRTIS-M between 8 and 14 April 2015, which are analysed in this work. During this period, 67P was approaching the Sun at a heliocentric distance of 1.9 AU and the coma activity was well developed and observable around the nucleus. The sequence of VIRTIS-M observations includes two types of coma scans: a) observations across the subsolar limb in which only the coma region located above the illuminated part of the nucleus is acquired, up to about $5 \mathrm{~km}$ altitude; b) observations 


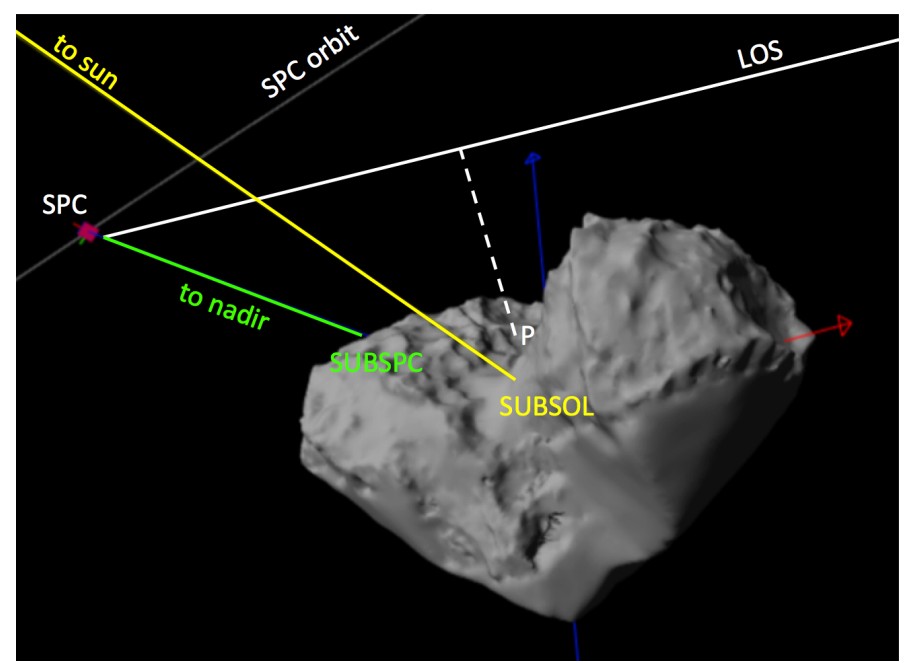

Fig. 1. Viewing and illumination geometry during coma observations. Lines correspond to solar direction (in yellow), nadir direction from the spacecraft (in green), and line of sight (LOS) through the coma (in white). The white dash line taken perpendicular to the LOS and passing through the comet nucleus centre defines the tangent altitude of a given point of the coma above the surface. Points P, SUBSOL, and SUBSPC are the tangent, subsolar, and subspacecraft points, respectively. Red and blue arrows indicate the $x$ and $z$ (rotation axis) directions of the comet.

taken at nadir, which include the full coverage of the nucleus and the coma surrounding it up to about $2.5 \mathrm{~km}$ from the limb. The instrumental spatial resolution during these observations ranged between 33 to $40 \mathrm{~m} / \mathrm{pixel}$, and the slit, oriented always perpendicular with respect to the 67P-Sun direction, is extended between 8.4 and $10.2 \mathrm{~km}$, depending on the spacecraft distance from the comet. Exposures varying between 1.5 and $6 \mathrm{~s}$ were commanded: in general, the short times are optimized for the nucleus observations while longer exposure times give better signal-to-noise ratio for the $\mathrm{H}_{2} \mathrm{O}$ coma emission. Short exposure times are used in case of $\mathrm{CO}_{2}$ coma emission to avoid spectral saturation of the thermal region, where the observed emission is located.

The geometry information relative to each VIRTIS-M pixel is calculated by a SPICE routine (Acton 1996) using the spacecraft's trajectory and orientation reconstructed kernels and 67P SHAP5 shape model (Jorda et al. 2016). The basic geometric quantities used to characterize pixels on the coma are shown in Fig. 1.

\subsection{Water and carbon dioxide column density retrievals}

Data were pre-treated with standard routines, including dark current and background corrections, flat-fielding, and wavelength calibration. A median filter was applied to the calibrated data along the samples and lines directions, in order to remove cosmic ray events and responsively out-of-range pixels and preserve the wavelength resolution. In each image acquired in nadir mode, as described in Sect. 2.2, the nucleus is masked on the basis of the proper geometry information, to avoid high contrast among adjacent pixels, which can induce scattering on the filter junctions. The mask is enlarged by seven pixels in all the directions (corresponding to a tangent altitude of about $400 \mathrm{~m}$ at the slant distances of the considered observations) to take the uncertainty in the comet's shape model into account. Despite this threshold, some regions of the nucleus still remain unmasked, but this does
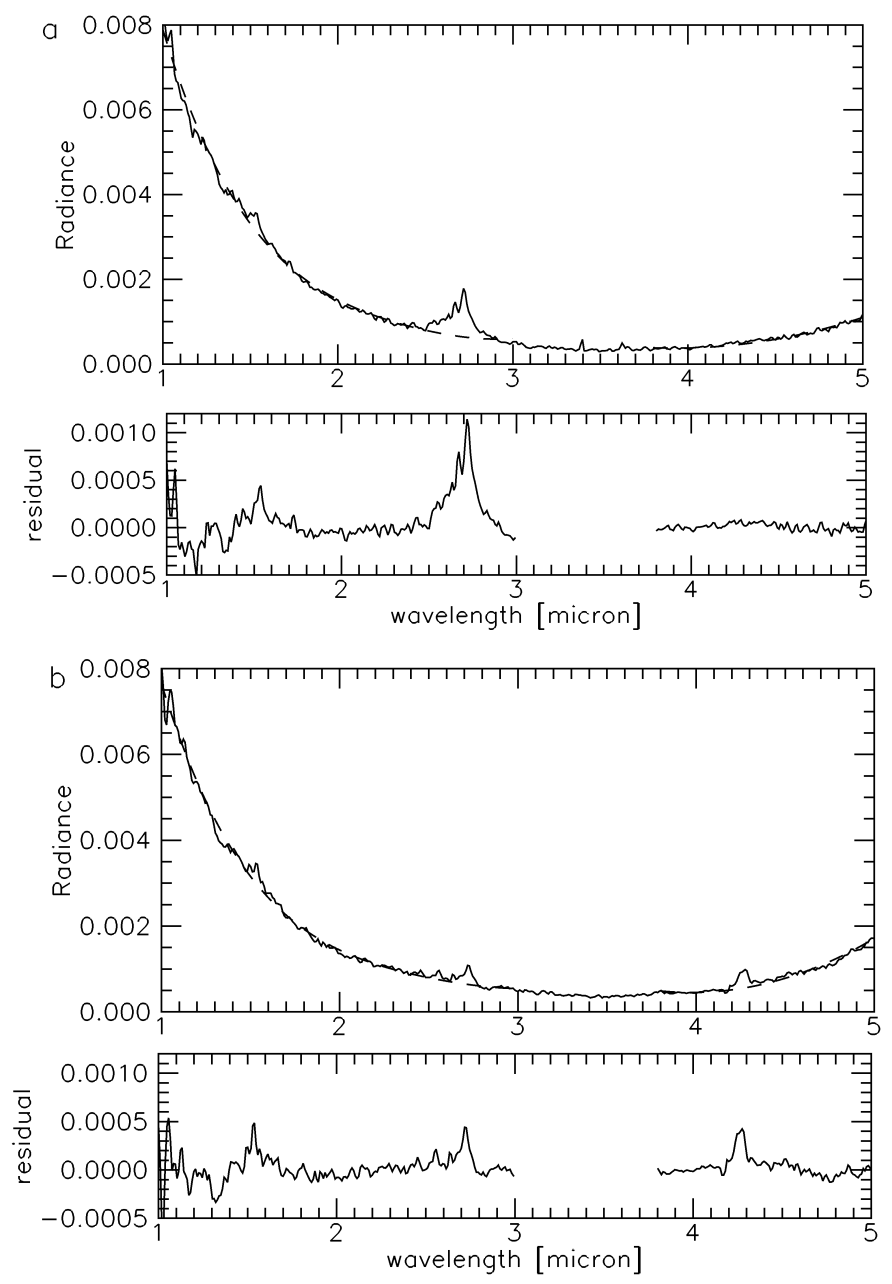

Fig. 2. a) Spectral radiance $\left(\mathrm{W} / \mathrm{m}^{2} / \mu \mathrm{m} / \mathrm{sr}\right)$ of comet $67 \mathrm{P}$ acquired with VIRTIS-M. It is obtained by averaging 30 spectra selected in the red region identified in Fig. $4 \mathrm{a}$. The $\mathrm{H}_{2} \mathrm{O}$ and $\mathrm{CO}_{2}$ emissions at $2.67 \mu \mathrm{m}$ and $4.27 \mu \mathrm{m}$ are observed. The continuum is fitted separately in the $1-3 \mu \mathrm{m}$ and 3.8-5.1 $\mu \mathrm{m}$ regions, using a $4-\mathrm{deg}$ and a $2-\mathrm{deg}$ polynomial functions respectively. The panel below the spectrum is the residual. b) The same as a), for the green region in Fig. 4. It is selected where a higher $\mathrm{CO}_{2}$ emission is detected.

not affect the results significantly. In this way, we are able to investigate the molecular emissions close to the nucleus. In addition, the enlarged mask also excludes the spectra that are too close to the nucleus from the computation, which may negatively affect the radiance coming from the coma just above. The radiance of the latter spectra, in fact, might include spurious signals due to the high contrast between the surface and the surrounding regions. These effects are caused by the instrumental point spread function and in-field stray light along the spectrometer's slit.

Figures 2a,b show two typical spectra acquired with VIRTIS. They are the result of an average of about 30 single spectral acquisitions, selected close to the neck (Fig. 2a) and the head (Fig. 2b) of the comet, respectively. The observed spectra show $\mathrm{H}_{2} \mathrm{O}$ and $\mathrm{CO}_{2}$ emissions at 2.6-2.76 $\mu \mathrm{m}$ and at $4.2-4.3 \mu \mathrm{m}$ respectively, superposed over a continuum, which is mainly due to scattering from the dust at the short wavelengths, but also to infield stray light coming from the nucleus. The two spectral regions considered for band intensity calculations are optimized in order to exclude possible signal alteration, which is caused by unexpected reflections on the VIRTIS filter junctions, as stated 
in Sect. 2.1. This is particularly important for the filters around $2.5 \mu \mathrm{m}$ and $4.3 \mu \mathrm{m}$, which are close to the coma emissions.

To evaluate the continuum, the spectra are fitted with a fouthdegree polynomial function from 1 to $3 \mu \mathrm{m}$, around the $\mathrm{H}_{2} \mathrm{O}$ emission, and with a second-degree function in the region from 3.8-5.1 $\mu \mathrm{m}$. In Fig. 2, the panels below the spectra show the residuals of the radiance fitted with the continuum. Residual values that are ten to twenty times lower than the emissions under study indicate that the continuum is properly evaluated, considering the fitting functions discussed above.

The fit with a fourth-degree function in the $1-3 \mu \mathrm{m}$ range is the best for describing the observed spectra mathematically. It is also reasonable to take the Rayleigh scattering into account; however, this assumption does not imply any conclusion on the optical and physical characteristics of the dust associated to the gas emission.

The $\mathrm{H}_{2} \mathrm{O}$ band is integrated from 2.6 to $2.76 \mu \mathrm{m}$, while a range from 4.2 to $4.3 \mu \mathrm{m}$ is included for the $\mathrm{CO}_{2}$ band area. The limited VIRTIS-M spectral resolution means that the rovibrational lines cannot be resolved. The spectral range selected for the band integration is chosen to agree with the values adopted for analysing VIRTIS-H data, where the higher spectral resolution allows the ro-vibrational structure of the $\mathrm{H}_{2} \mathrm{O} v_{3}$ and possibly the $v_{1}$ bands to be partly resolved (Bockelée-Morvan et al. 2015). In the case of $\mathrm{CO}_{2}$, the considered wavelength region encompasses the $v_{3}$ band. Considering the high variability of the signal-to-noise ratio in the processed dataset, the $\mathrm{H}_{2} \mathrm{O}$ with $\mathrm{CO}_{2}$ average band area errors are $15 \%$ and $10 \%$, respectively, calculated by propagating the formal errors.

Band area $(I)$ is converted to column density $(N)$, adopting the $g$-factors $\left(g_{f}\right)$ at $1 \mathrm{AU}$ equal to $3.349 \times 10^{-4} \mathrm{~s}^{-1}$ (Villanueva et al. 2012) and $2.86 \times 10^{-3} \mathrm{~s}^{-1}$ (Crovisier \& Encrenaz 1983) for $\mathrm{H}_{2} \mathrm{O}$ and $\mathrm{CO}_{2}$, respectively. The two quantities are related through the equation

$I=\frac{h v}{4 \pi} g_{f} \frac{1}{R^{2}}\langle N\rangle$

where $N$ is in $\mathrm{m}^{-2}, I$ is expressed in $\mathrm{W} \mathrm{m}^{-2} \mathrm{sr}^{-1}, v$ is the central frequency of the band, and $R$ is the heliocentric distance of each observation in AU, as reported in Table A.1 (see parameter named Distance).

\subsection{Optical depth effects}

Debout et al. (2016) performed radiative transfer modelling for the $\mathrm{H}_{2} \mathrm{O}$ and $\mathrm{CO}_{2} v_{3}$ bands observed at $2 \mathrm{AU}$ from the Sun with VIRTIS. Optical depth has an influence on both the local excitation rate by the Sun radiation and the received radiation. Since the gas flow is radial and the exciting source unidirectional, the attenuation of the band intensity is a function of both the phase and azimuthal angles (Gersch \& A'Hearn 2014; Debout et al. 2016). For a phase angle of $90^{\circ}$, opacity effects are exacerbated when the azimuthal angle (angle between the Sun direction and the line from the pixel footprint to comet centre) is equal to $a z=0^{\circ}$, whereas they are minimized for $a z=90^{\circ}$. We define the factor attenuation $f$ as the ratio between the received radiation and that expected under optically thin conditions.

Figure 3 shows the attenuation factor of the $\mathrm{H}_{2} \mathrm{O}$ and $\mathrm{CO}_{2}$ $v_{3}$ bands as a function of column density derived from the calculations of Debout et al. (2016). Calculations shown in this figure correspond to $a z=45^{\circ}$, a phase angle of $90^{\circ}$ (i.e., representative of the viewing geometry for the maximum molecular emissions), and isotropic gas production with total $\mathrm{H}_{2} \mathrm{O}$ and $\mathrm{CO}_{2}$ production

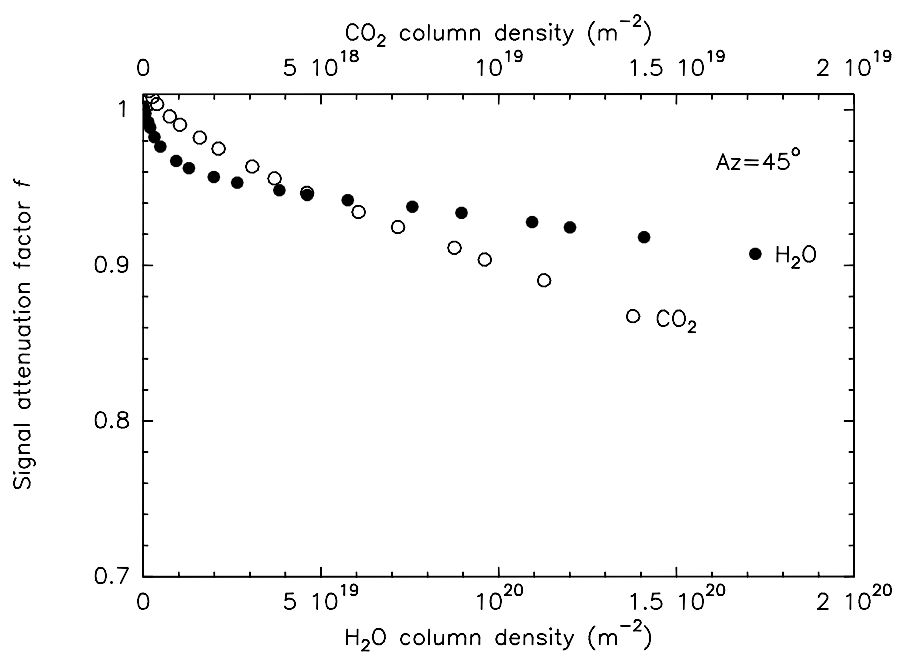

Fig. 3. Signal attenuation ratio $(f)$ as a function of column density from the calculations of Debout et al. (2016). Plain symbols are for the $\mathrm{H}_{2} \mathrm{O}$ $v_{3}$ band, with the column density scale given in the bottom $x$-axis. Open symbols are for the $\mathrm{CO}_{2} v_{3}$ band, with the column density scale given in the top $x$-axis. Calculations correspond to an azimut of $45^{\circ}$, a phase angle of $90^{\circ}$, a heliocentric distance of $2 \mathrm{AU}$, and isotropic gas production with total $\mathrm{H}_{2} \mathrm{O}$ and $\mathrm{CO}_{2}$ production rates of $10^{27}$ and $8 \times 10^{25} \mathrm{~s}^{-1}$, respectively. The highest column densities correspond to altitudes of 0.2 , $0.5,0.8,1.0,1.50,2.0,3.0 \mathrm{~km}$, with the column density decreasing with increasing altitude.

rates of $10^{27}$ and $8 \times 10^{25} \mathrm{~s}^{-1}$. For both molecules, the highest column densities for which the factor $f$ is given correspond to an altitude of $0.2 \mathrm{~km}$. For $\mathrm{H}_{2} \mathrm{O}$, this parameter is $>0.90$ for column densities below $1.7 \times 10^{20} \mathrm{~s}^{-1}$. Based on additional calculations with higher water production rates, we estimate $f \sim 0.80$ for the high $\left(\sim 10^{21} \mathrm{~m}^{-2}\right)$ column densities observed above the neck region. As for $\mathrm{CO}_{2}$, measured column densities (deduced from the optically thin assumption) are below $2 \times 10^{19} \mathrm{~s}^{-1}$. The factor $f$ is $>0.86$ for this range of $\mathrm{CO}_{2}$ column density (Fig. 3). The small variation of $f$ with decreasing altitude results from the increase in coma temperature, which minimizes opacity effects. Altogether we can conclude that coma regions showing large emissions are affected by opacity effects by no more than $15 \%$ for $\mathrm{CO}_{2}$ and $20 \%$ for $\mathrm{H}_{2} \mathrm{O}$.

We evaluated that the highest attenuation occurs at azimuth angles of $157^{\circ} \leq a z \leq 180^{\circ}$ for $\mathrm{H}_{2} \mathrm{O}$ and $113^{\circ} \leq a z \leq 180^{\circ}$ for $\mathrm{CO}_{2}$ within $1 \mathrm{~km}$ of the nucleus where molecules are not excited because of shadowing. Considering these limits, about $6 \%$ of the available $\mathrm{CO}_{2}$ spectra in the VIRTIS dataset listed in Table A.1 are affected by opacity, while the percentage is lower than $1 \%$ for $\mathrm{H}_{2} \mathrm{O}$. Since the effect is marginally significant only for a very small fraction of the total, we decided to mantain them in the set of analysed data owing to the negligible net impact on the results obtained so far.

\section{Results}

Figure 4 shows the $\mathrm{H}_{2} \mathrm{O}$ and $\mathrm{CO}_{2}$ emission distribution around the nucleus in the case of image I1_00387442903 acquired on 12 April 2015. Panel (a) shows the comet image at $1.095 \mu \mathrm{m}$, where several features can be identified. Since the gas emission is associated with dust flow, many of these features can be ascribed to dust itself. Once the signal has been cleaned from continuum, as described in Sect. 2.3, the real gas emission appears as shown in Fig. 4a by the coloured contour lines, which refer 

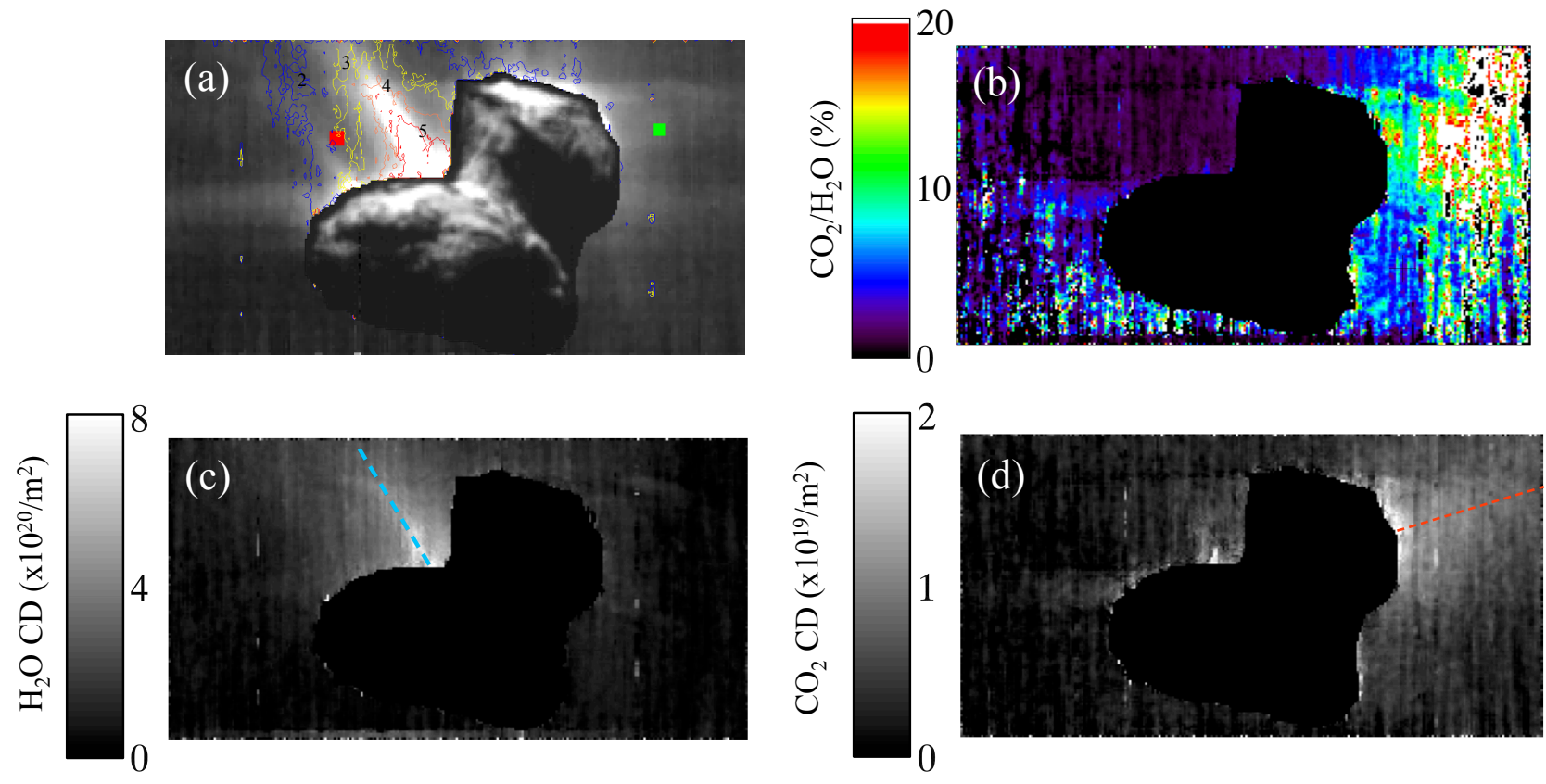

Fig. 4. a) Composite image showing the comet's nucleus at $1.095 \mu \mathrm{m}$, and the water column density superimposed. Contour lines in the coma indicate the retrieved $\mathrm{H}_{2} \mathrm{O}$ column density values ranging from $2 \times 10^{20} \mathrm{~m}^{-2}$ (blue line) to $5 \times 10^{20} \mathrm{~m}^{-2}$ (red line). The image number is $I 1 \_00387442903$, acquired on 12 April 2015, and shown in Fig. 6e. The observed jets are caused by dust particles, while water is exclusively located in the coma above the neck, as shown in Panel c). The red and green boxes indicate the pixels averaged to provide the mean spectra seen in Fig. 2a, b, respectively. b) $\mathrm{CO}_{2}$ to $\mathrm{H}_{2} \mathrm{O}$ ratio for the considered VIRTIS image. c) Water column density of the VIRTIS image, obtained as explained in the text. The dashed line indicates the radial direction considered for the profiles in Fig. 5a. d) $\mathrm{CO}_{2}$ column density of the VIRTIS image, obtained as explained in the text. The dashed line indicates the radial profile considered for the profiles in Fig. 5b.

to the water vapour column density as an example. The retrieved column density values range from $2 \times 10^{20} \mathrm{~m}^{-2}$ to $5 \times 10^{20} \mathrm{~m}^{-2}$. Figure $4 \mathrm{~b}$ gives the $\mathrm{CO}_{2}$ to $\mathrm{H}_{2} \mathrm{O}$ column density ratio, as mapped above the considered image. The maximum value is observed on the right-hand side of the map, appearing above the comet's head in this perspective but originating in the southern hemisphere immediately behind it, while the $\mathrm{CO}_{2} / \mathrm{H}_{2} \mathrm{O}$ column density ratio reaches only a few percent in the neck region. This parameter reveals a strong asymmetry in the distribution of the gas emissions for the two species and suggests that $\mathrm{H}_{2} \mathrm{O}$ is more localized in the comet's neck region, while $\mathrm{CO}_{2}$ is more diffused. The same is easily found in Panels (c) and (d), where $\mathrm{H}_{2} \mathrm{O}$ and $\mathrm{CO}_{2}$ column densities are shown, respectively.

To trace the vertical variability of the $\mathrm{H}_{2} \mathrm{O}$ and $\mathrm{CO}_{2}$ emissions above the comet's nucleus, we considered two radial profiles taken across the maximum emissions of $\mathrm{H}_{2} \mathrm{O}$ (blue dashed line in Fig. 4c) and $\mathrm{CO}_{2}$ (red dashed line in Fig. 4d). The tangent point of the profile passing through the maximum water emission corresponds to Seth-Hapi region, at longitude $269^{\circ}$, latitude $33^{\circ} \mathrm{N}$, and local solar time $13 \mathrm{~h}$. The tangent point of the profile passing through the maximum $\mathrm{CO}_{2}$ emission is in the southern hemisphere of the comet, at longitude $353^{\circ}$, latitude $23^{\circ} \mathrm{S}$, and observed at a local solar time of about $19 \mathrm{~h}$. It is located in the Hatmehit-Bastet region, according to the surface division proposed by Thomas et al. (2015). Figure 5 provides the $\mathrm{H}_{2} \mathrm{O}$ and $\mathrm{CO}_{2}$ emission trends as a function of distance from the nucleus along the profiles in Figs. 4c, d, respectively, as indicated by the dashed lines. Water emission is about ten times more intense in the Seth-Hapi region, as confirmed by the two corresponding profiles shown in Fig. 5, while $\mathrm{CO}_{2}$ is slightly higher in the Hatmehit-Bastet region than in Seth-Hapi. Considering the high variability of the signal on single spectra, hence the variability of the column density retrieved values, the profiles are fitted before calculating the $\mathrm{CO}_{2} / \mathrm{H}_{2} \mathrm{O}$ ratio, shown in Panels (c) and (d) of Fig. 5 for the two comet's regions.

Above the Seth-Hapi region, the $\mathrm{CO}_{2}$ to $\mathrm{H}_{2} \mathrm{O}$ ratio shows a slight decrease when moving away from the nucleus up to $2 \mathrm{~km}$, followed by a slight increase in the $\mathrm{CO}_{2}$ content. Because of the low $\mathrm{CO}_{2}$ column densities retrieved in this region, the ratio is lower than $1.5 \%$ at all the considered tangent altitudes. Conversely, above the Hatmehit-Bastet region, this parameter is about ten times greater, reaching a maximum value of $35 \%$ at about $3 \mathrm{~km}$ from the nucleus. The $\mathrm{CO}_{2}$ to $\mathrm{H}_{2} \mathrm{O}$ ratio increases when moving away from the nucleus, because the water content decreases more rapidly than carbon dioxide. This could be caused by the water source region being localized in a small area in the neck, while $\mathrm{CO}_{2}$ distribution is spread more over the southern latitudes. However, these results apply only along the considered tangent profiles, and care is required when considering the entire dataset.

The variability of the $\mathrm{H}_{2} \mathrm{O}$ and $\mathrm{CO}_{2}$ emissions is typical of these bodies and might reflect differences in composition of the cometary nucleus. It can be also due to fluctuations of the emissions themselves because of the different illumination conditions. In the following we analyse the $\mathrm{H}_{2} \mathrm{O}$ and $\mathrm{CO}_{2}$ column density distributions around comet $67 \mathrm{P}$, as observed at different rotational phases.

\subsection{Water column density sequence}

Figure 6 shows the water column density distribution in the inner coma for nine composite images acquired from 11 to 13 April 2015, and identified with the italic character in Table A.1. The comet nucleus is a real image acquired at $1.095 \mu \mathrm{m}$ with VIRTIS-M, where it is possible to qualitatively identify the illuminated and dark regions of 67P. The sequence includes nine 

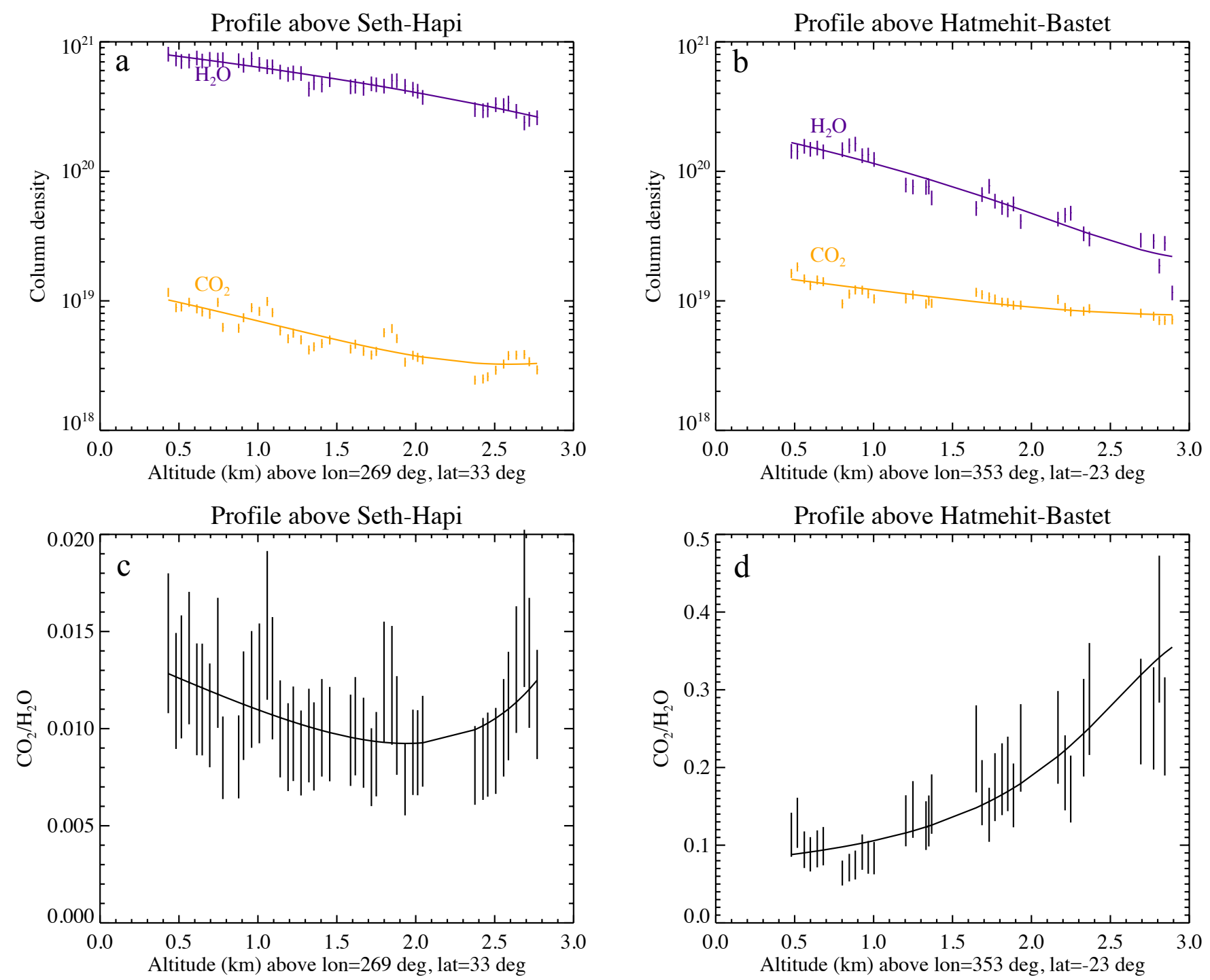

Fig. 5. a) $\mathrm{H}_{2} \mathrm{O}$ and $\mathrm{CO}_{2}$ radial variation in the Seth-Hapi region, along the profile indicated by the dashed line in Fig. 4c. b) The same as in the panel a for the region Hatmehit-Bastet, along the profile in Fig. 4d. c) $\mathrm{CO}_{2}$ to $\mathrm{H}_{2} \mathrm{O}$ ratio in the Seth-Hapi region, obtained from the single profiles in the same region shown in panel a. d) The same as in Panel c) for the $\mathrm{CO}_{2}$ and $\mathrm{H}_{2} \mathrm{O}$ profiles retrieved in Hatmehit-Bastet region.

non-consecutive images, and it covers $49 \mathrm{~h}$ in total, or about four full rotations of the comet. The Sun direction is towards the top of each image.

The water outgassing is mostly concentrated in the comet's neck regions. In some cases, like images I1_00387379010, I1_00387554894, I1_003875558495 (see Figs. 6a, h, i), water emission is observed above the southern regions of the comet, but still emitted from the neck. In images I1_0038754871 and I1_00387481450 (Figs. 6b, c), a well-structured emission jet is observed in the direction opposite the observer. However, one limitation of our analysis is that we cannot be sure where the emissions really come from, because the observed jets could come from a hidden region of the comet that is not directly visible in the image.

An analysis of the wide-angle images acquired by the OSIRIS camera on Rosetta from August 2014 to September 2014 provides preliminary results for the jets, morphologies, and dynamics, and identifies peculiar regions in the neck where jets are likely to originate (Lin et al. 2015). The geometry files, which are associated with VIRTIS observations of the same region under different viewing perspectives, could in principle provide the tools for tracing back the jets like a stereoscopic camera, as already demonstrated for the OSIRIS images. This procedure is quite time-demanding considering the complexity of the jet morphology, the molecules dynamics, and their interactions with the Sun and dust particles. This processing is under consideration as a topic of a future paper.

\subsection{Carbon dioxide column density sequence}

The same investigation is applied to the carbon dioxide emission, centred at $4.27 \mu \mathrm{m}$. The $\mathrm{CO}_{2}$ band emission (see Fig. 7) is on average $10^{19}$ molecules s${ }^{-1}$. The $\mathrm{CO}_{2}$ column density is quite weak above the neck region, while it is diffused in the head and Southern regions. The same behaviour was highlighted in observations for the period 24 November 2014 to 24 January 2015 (Bockelée-Morvan et al. 2015). It seems, moreover, that $\mathrm{CO}_{2}$ emission is not as strictly linked to the solar illumination, unlike for the case of water vapour.

\subsection{Water column density vertical distribution maps}

The 3D distribution of $\mathrm{H}_{2} \mathrm{O}$ column density is studied by examining the emission as a function of tangent altitude above 


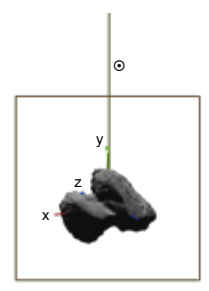

$\mathrm{a} \varphi=0$
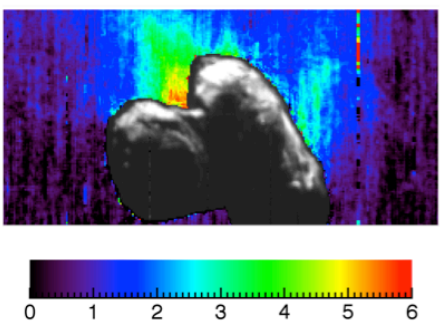

$\mathrm{d} \varphi=0.339$
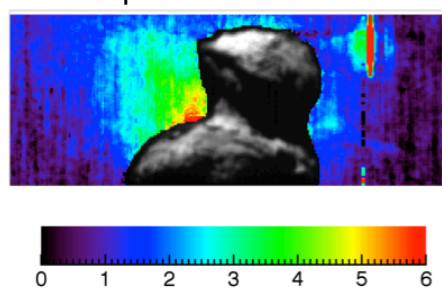

$g \varphi=0.461$
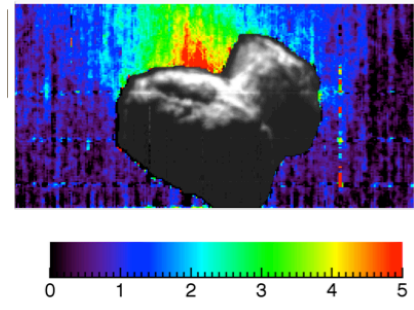

b $\varphi=0.239$
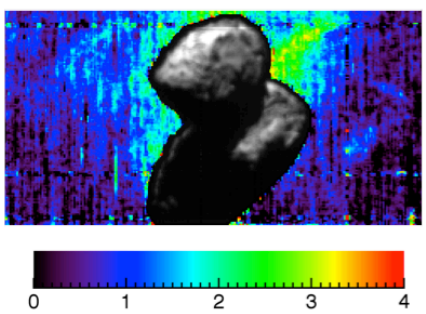

e $\varphi=0.393$
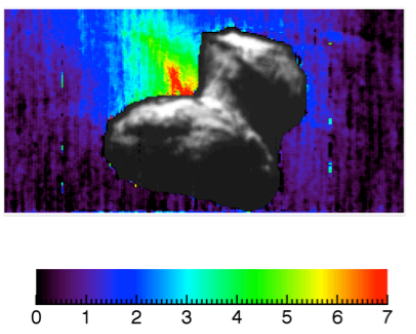

h $\varphi=0.916$
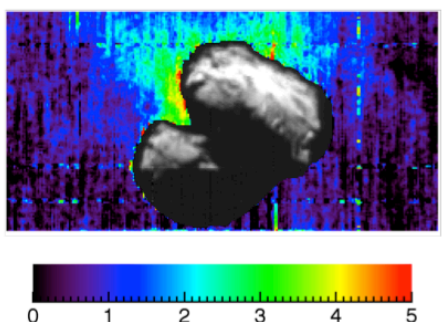

c $\varphi=0.258$

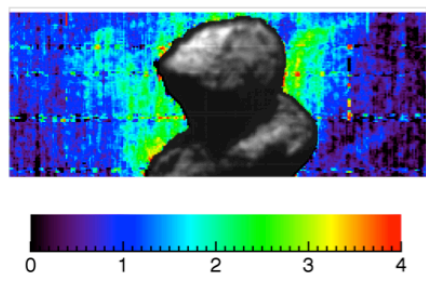

f $\varphi=0.420$
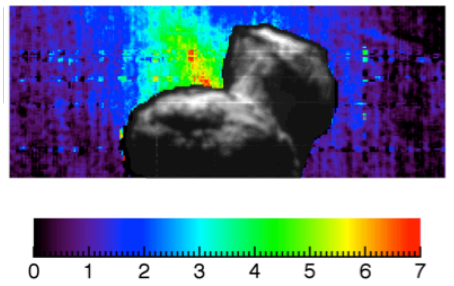

i $\varphi=0.997$
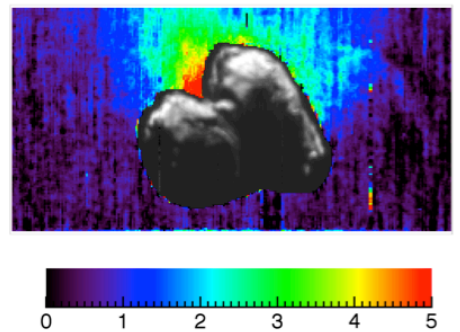

Fig. 6. $\mathrm{H}_{2} \mathrm{O}$ column density retrieved on nine VIRTIS-M images, acquired from 11 to 13 April 2015 at rotational phases $\phi$. Image details are provided in Table A.1, as identified with the italic character. In the images a), h), i), emissions are located in the southern hemisphere. Intensities are provided in terms of $10^{20}$ molecules $\mathrm{m}^{-2}$. The simulation on the left with respect to the water maps shows the comet's $x, y, z$ axes, and the Sun direction for the images a), d), and $\mathbf{g})$. The square is the full $\left(3.6^{\circ} \times 3.6^{\circ}\right)$ VIRTIS-M field of view. It corresponds to the images horizontal width, while the vertical size depends on the number of consecutive lines acquired for each image.

the nucleus as defined in Fig. 1. The latitude and longitude values of the tangent point $(\mathrm{P})$ are used to identify the closest region on the nucleus along the radial axis associated with the coma emission. As shown in Fig. 1, the tangent point $(\mathrm{P})$ on the surface is defined along the line perpendicular to the line of sight and passing through the nucleus centre. Each VIRTIS-M pixel is therefore associated a tangent altitude, a tangent point on the surface, and a local solar time. Given the highly irregular shape of the nucleus, especially in the Hapi region, on the surface there could be other points than the tangent point that are closer to the line of sight.

However, it could be possible that neither the closest point nor the tangent point are the main source of activity for a given observation. This is more likely if the closest point is in a region of weak activity. Given the complexity of the geometry computation, for the purposes of this work we have used the tangent point to correlate gas emissions in the coma with the nucleus surface reference system.

The data studied cover almost all the longitudes at middle latitudes, from about $55^{\circ} \mathrm{N}$ to $54^{\circ} \mathrm{S}$, although the coverage is quite patchy. Figure 8 shows the cylindrical maps of the $\mathrm{H}_{2} \mathrm{O}$ column density projected above the nucleus at different altitudes. Most of the data are concentrated within $3 \mathrm{~km}$ from the nucleus, while at altitudes higher than $3 \mathrm{~km}$ the number of available coma detections decreases by a factor of 3 , on average. The traces in each map follow the trajectory of the tangent point over the surface during the time of observations. The median value of the column density calculated for all coma pixels having a tangent altitude between $0.5-1.0,1.0-2.0,2.0-3.0$, and $\geq 3.0 \mathrm{~km}$ from the surface is given on the maps regardless of the local solar time (LST). Each map has a resolution of $1 \times 1 \mathrm{deg}$ in lat-lon. The truecolour albedo map of the comet (Ciarniello et al. 2015), shown in Fig. 8e, is used as a reference to correlate the gas emission distribution with the surface's regions. The $\mathrm{H}_{2} \mathrm{O}$ column density distribution clearly shows two areas of maximum emission corresponding to the Aten-Babi $\left(25^{\circ} \leq\right.$ lon $\leq 90^{\circ}, 5^{\circ} \leq$ lat $\left.\leq 50^{\circ}\right)$ and Seth-Hapi active regions $\left(215^{\circ} \leq\right.$ lon $\leq 305^{\circ}, 5^{\circ} \leq$ lat $\left.\leq 50^{\circ}\right)$ at all the considered tangent altitudes.

\subsection{Carbon dioxide column density vertical distribution maps}

The same analysis performed in the previous section for $\mathrm{H}_{2} \mathrm{O}$ is repeated for $\mathrm{CO}_{2}$ (see Fig. 9). The better coverage is concentrated within $3 \mathrm{~km}$ of the nucleus. The $\mathrm{CO}_{2}$ column density monotonically decreases with distance from the nucleus. The $\mathrm{CO}_{2}$ emission is higher above the nucleus southern hemisphere, although the distribution is on average more uniform than for $\mathrm{H}_{2} \mathrm{O}$. In particular, the regions corresponding to AtenBabi, where the $\mathrm{H}_{2} \mathrm{O}$ emission is stronger, show a depletion of $\mathrm{CO}_{2}$ emission in almost all the maps (Fig. 9). Conversely, a local maximum is observed at $270^{\circ} \leq$ lon $\leq 315^{\circ}, 30^{\circ} \leq$ lat $\leq 45^{\circ}$, at $1-2 \mathrm{~km}$ and $2-3 \mathrm{~km}$ from the nucleus, in the Hapi region. In addition, a second local maximum is identified at the border of 

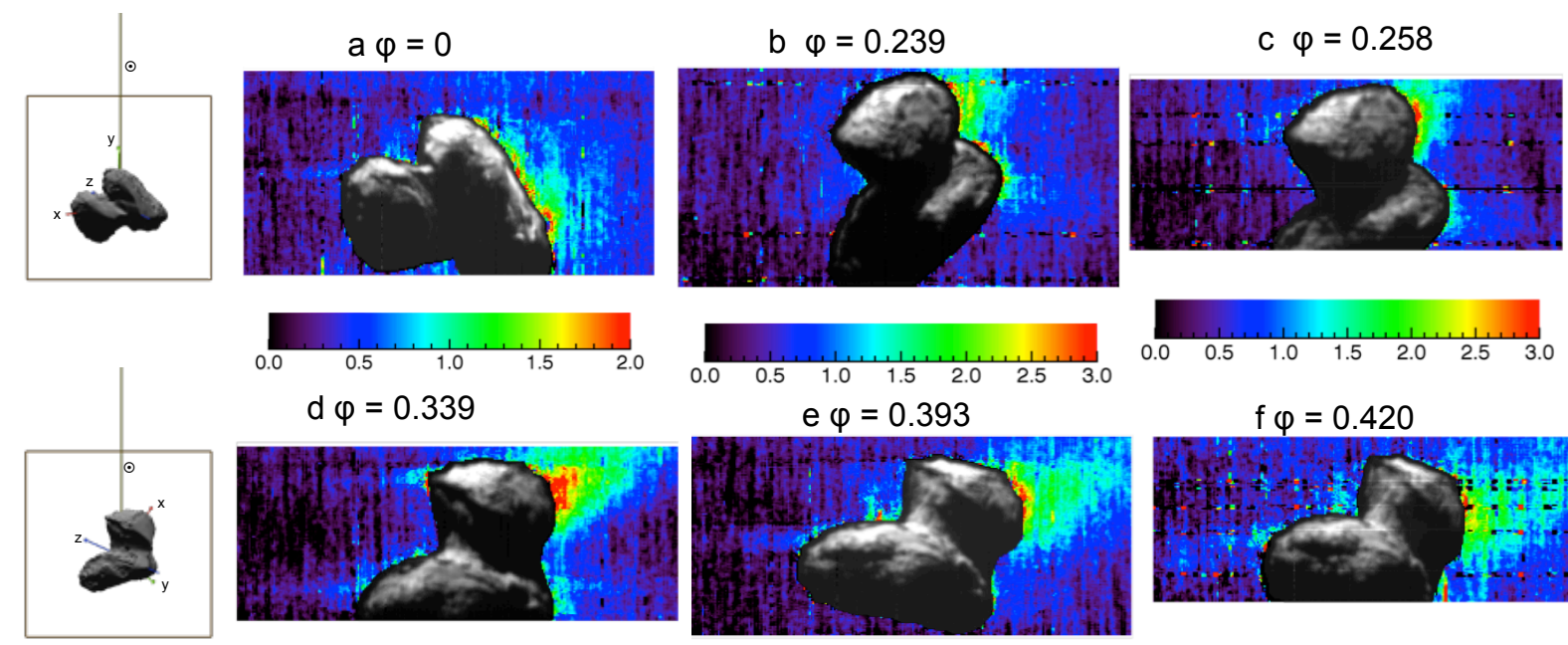

$\mathrm{d} \varphi=0.339$
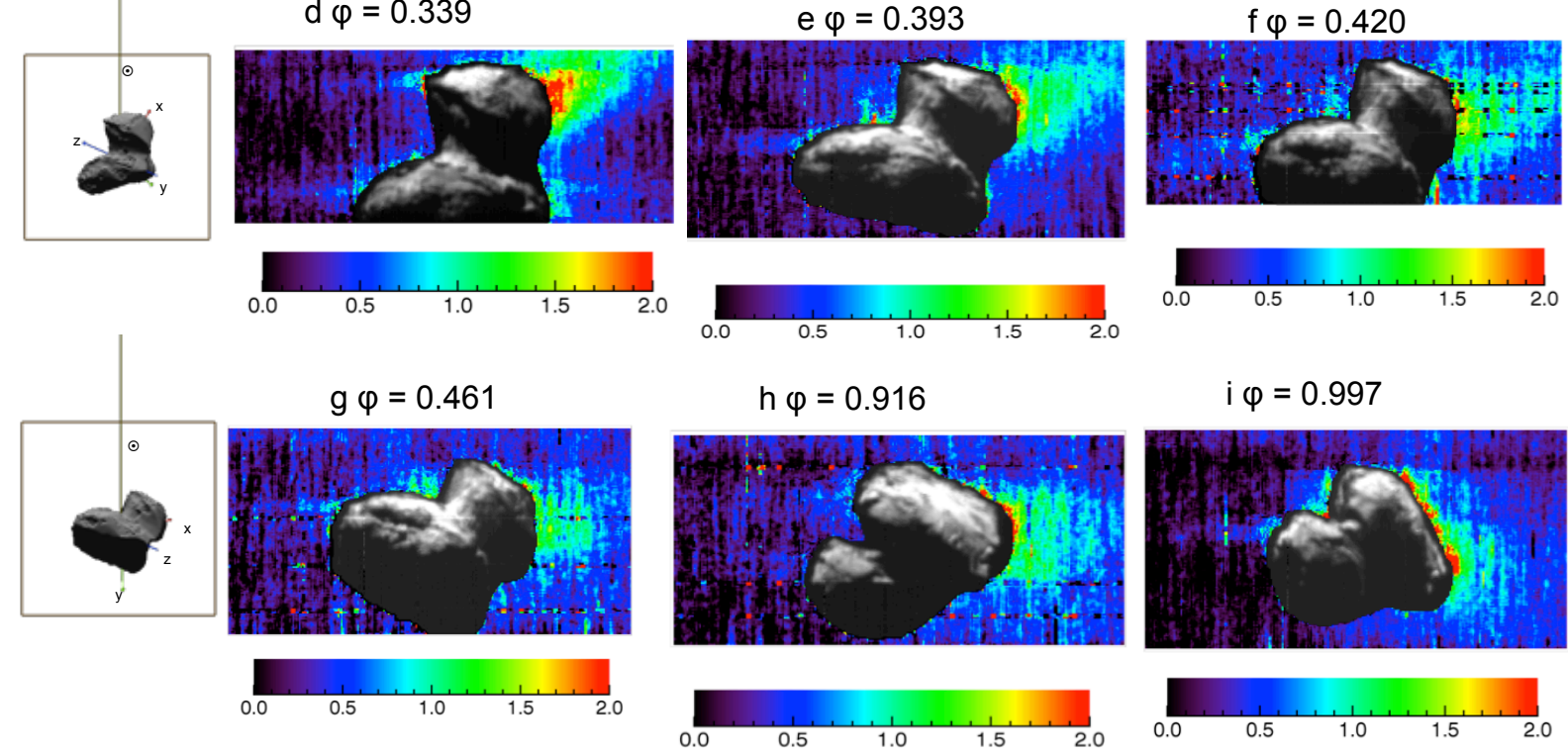

Fig. 7. As in Fig. 6, showing the $\mathrm{CO}_{2}$ column density for a sequence of nine VIRTIS-M images. The $\mathrm{CO}_{2}$ outgassing mostly occurs in the head of

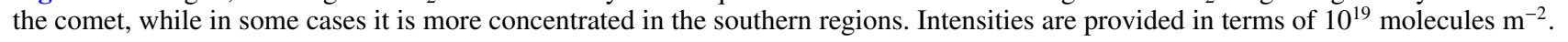

Imothep region $\left(135^{\circ} \leq\right.$ lon $\leq 180^{\circ}$, equatorial lat $)$, more evident at tangent altitudes of $2-3 \mathrm{~km}$.

\section{Discussion}

VIRTIS-M observations allow us to infer the distribution of water around the comet's nucleus. The emission is maximum in two active regions located in the comet's neck, Aten-Babi, and SethHapi. In contrast, $\mathrm{CO}_{2}$ emission appears quite diffused around the nucleus. This behaviour is evident in images of $\mathrm{CO}_{2}$ column density around the nucleus shown in Fig. 7, but also in the mean maps, in Fig. 9. On Hapi, VIRTIS has observed the diurnal cycle of water ice, condensing during the nighttime and sublimating at dawn (De Sanctis et al. 2015). The resulting intense water vapour outgassing has been observed by VIRTIS also in the coma above the same region.

Our analysis suggests that $\mathrm{CO}_{2}$ is depleted in the comet's neck where, conversely, $\mathrm{H}_{2} \mathrm{O}$ is more abundant. Nucleus shape, spin axis orientation, and orbital characteristics indicate that we are observing a very peculiar bilobate object: the small head receives the maximum solar flux at a heliocentric distance of $2 \mathrm{AU}$, while the larger body unit is fully illuminated during the perihelion passage at 1.2 AU. Moreover, the spin axis orientation with respect to the orbital plane implies that for a given time a large portion of the surface is never illuminated by the Sun. These characteristics are therefore driving the activation of the volatiles sublimation occurring in the different places of the surface. This is shown by the different concentration and emission of the major species discussed in the present work, which
Table 1. $\mathrm{CO}_{2}$ to $\mathrm{H}_{2} \mathrm{O}$ ratio (in \%) above Aten-Babi, Seth-Hapi, and Imothep active regions.

\begin{tabular}{cc}
\hline \hline Region & $\mathrm{CO}_{2} / \mathrm{H}_{2} \mathrm{O}$ \\
& $(\%)$ \\
\hline Aten - Babi & $2.4 \pm 0.6$ \\
Seth - Hapi & $3.0 \pm 0.7$ \\
Imothep & $3.9 \pm 1.0$ \\
\hline
\end{tabular}

could also imply a different thermal history of the northern and southern hemispheres of the comet. This different thermal history could explain the excess of $\mathrm{CO}_{2}$ in the southern latitudes.

Figure $10 \mathrm{~b}$ presents the $\mathrm{CO}_{2}$ to $\mathrm{H}_{2} \mathrm{O}$ column density ratio for the considered period, as projected on the comet's surface. To derive the map, all the data with a tangent altitude greater than $0.5 \mathrm{~km}$ are used. The corresponding $\mathrm{H}_{2} \mathrm{O}$ and $\mathrm{CO}_{2}$ maps are shown in Panels (c) and (d), respectively. Panel (a) provides the regions identified on the comet's surface as named by Thomas et al. (2015). The $\mathrm{CO}_{2}$ to $\mathrm{H}_{2} \mathrm{O}$ column density ratio is higher at the southern latitudes, confirming that $\mathrm{CO}_{2}$ tends to outgass in these regions. The southern hemisphere was less illuminated in the period considered for this work, so this should be taken into account to explain the smaller water abundance in these regions.

In Table 1 , the $\mathrm{CO}_{2}$ to $\mathrm{H}_{2} \mathrm{O}$ column density ratio is reported, as calculated for the water active regions, Aten-Babi and Seth-Hapi, and above Imothep. The value is quite constant above the water active regions, while it is higher on Imothep. Considering the lower illumination conditions of the southern 

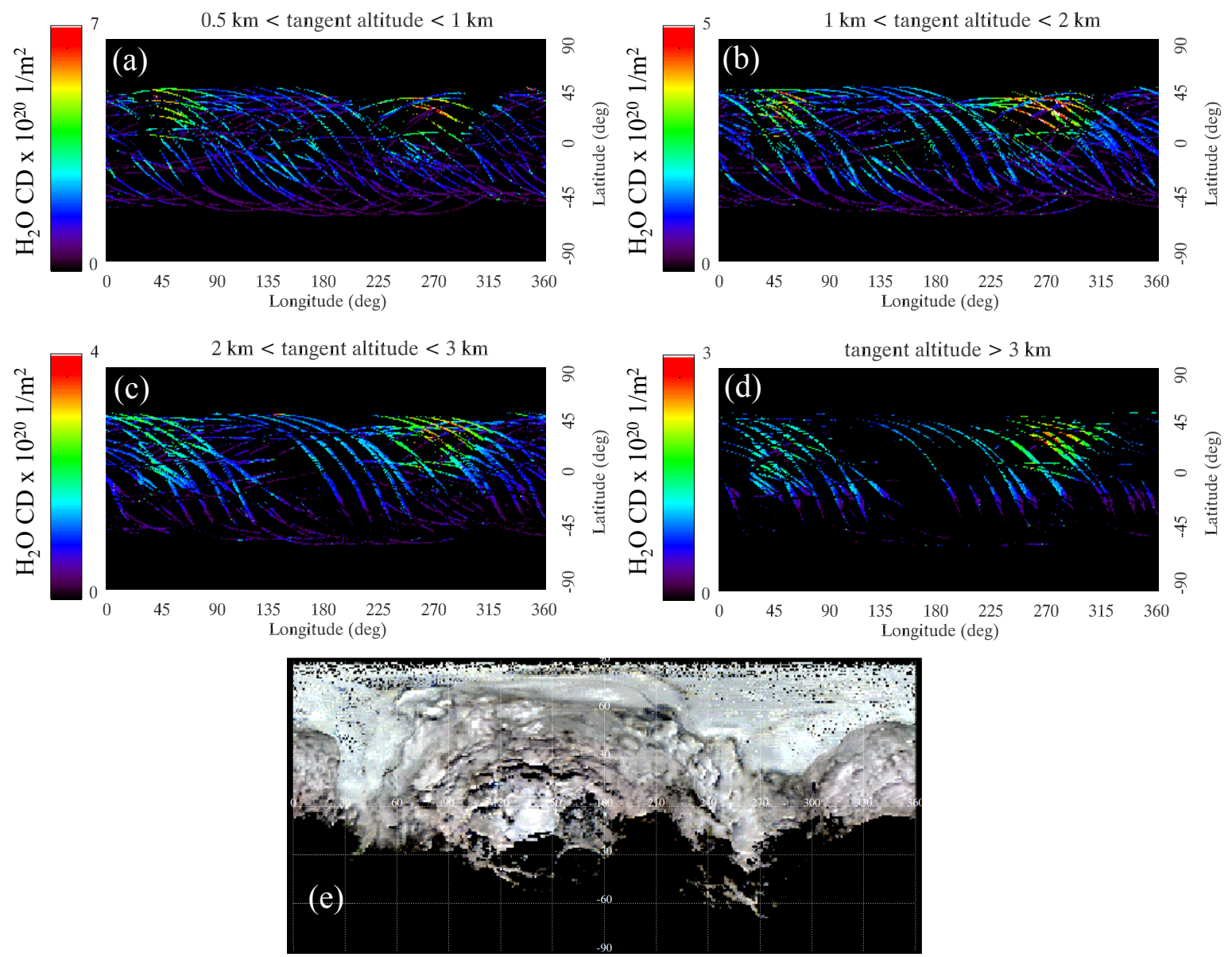

Fig. 8. a) Cylindrical map of the $\mathrm{H}_{2} \mathrm{O}$ column density for data with a tangent altitude between $0.5 \mathrm{~km}$ and $1 \mathrm{~km}$ at any LST. VIRTIS-M pixels are identified on the surface by means of the position of the tangent point. Points having a column density exceeding the maximum value indicated by the colour ramp are marked in white. b) to d) The same map distribution for $1 \leq$ tangent altitude $\leq 2.0 \mathrm{~km}, 2.0 \leq$ tangent altitude $\leq 3.0 \mathrm{~km}$ and for tangent altitude $\geq 3.0 \mathrm{~km}$ is shown. e) True colour albedo map from Ciarniello et al. (2015), as a reference.
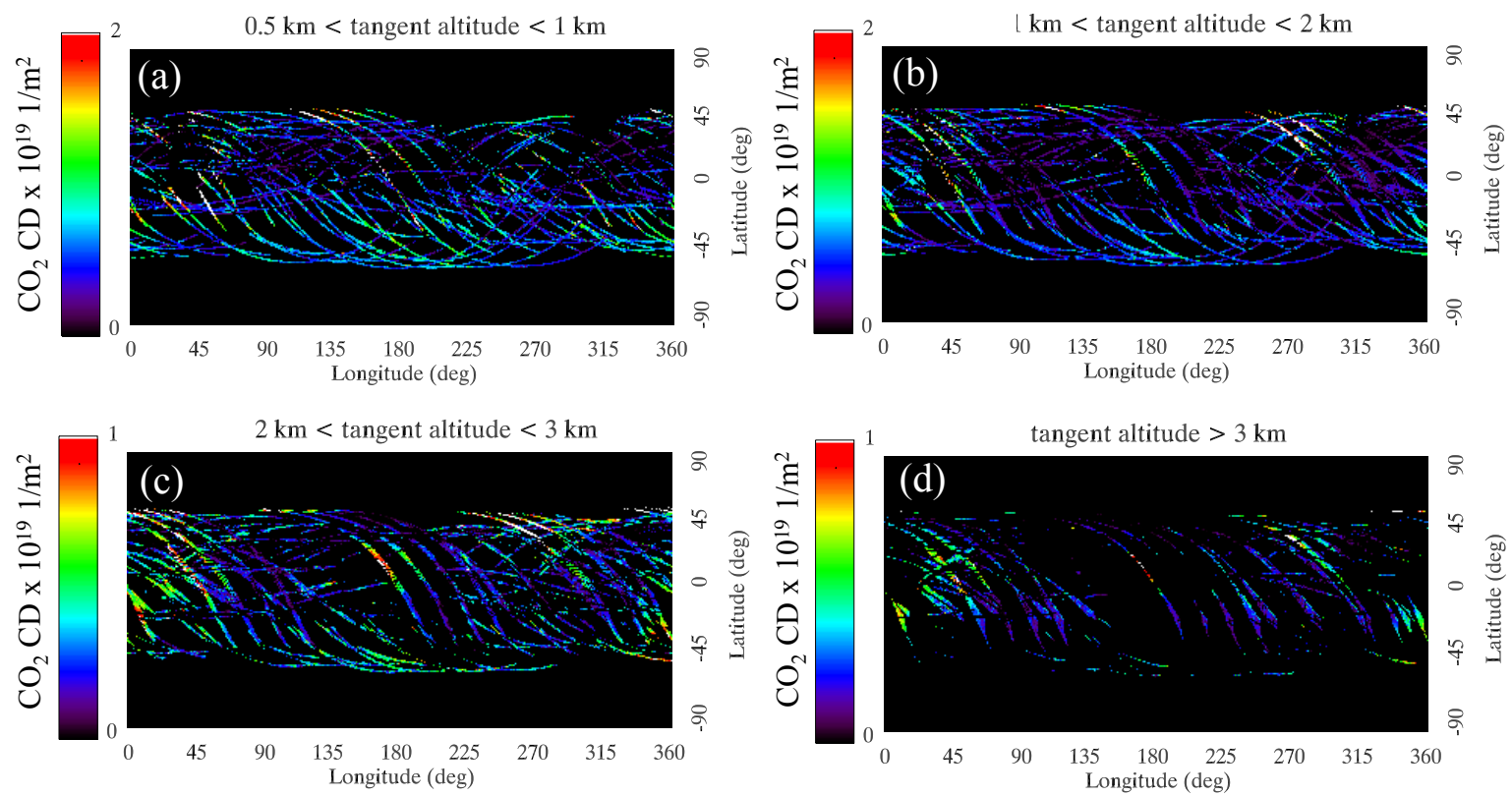

Fig. 9. a) Cylindrical map of the $\mathrm{CO}_{2}$ column density for $0.5 \leq$ tangent altitude $\leq 1 \mathrm{~km}$ at any LST. VIRTIS-M pixels are identified on the surface by means of the position of the tangent point. Points having a column density exceeding the maximum value indicated by the colour ramp are marked in white. The same maps for different altitude bins $(1 \leq$ tangent altitude $\leq 2.0 \mathrm{~km}, 1.0 \leq$ tangent altitude $\leq 3.0 \mathrm{~km}$ and for tangent altitude $\geq$ $3.0 \mathrm{~km}$ ) are also shown (panels from b) to d)). 

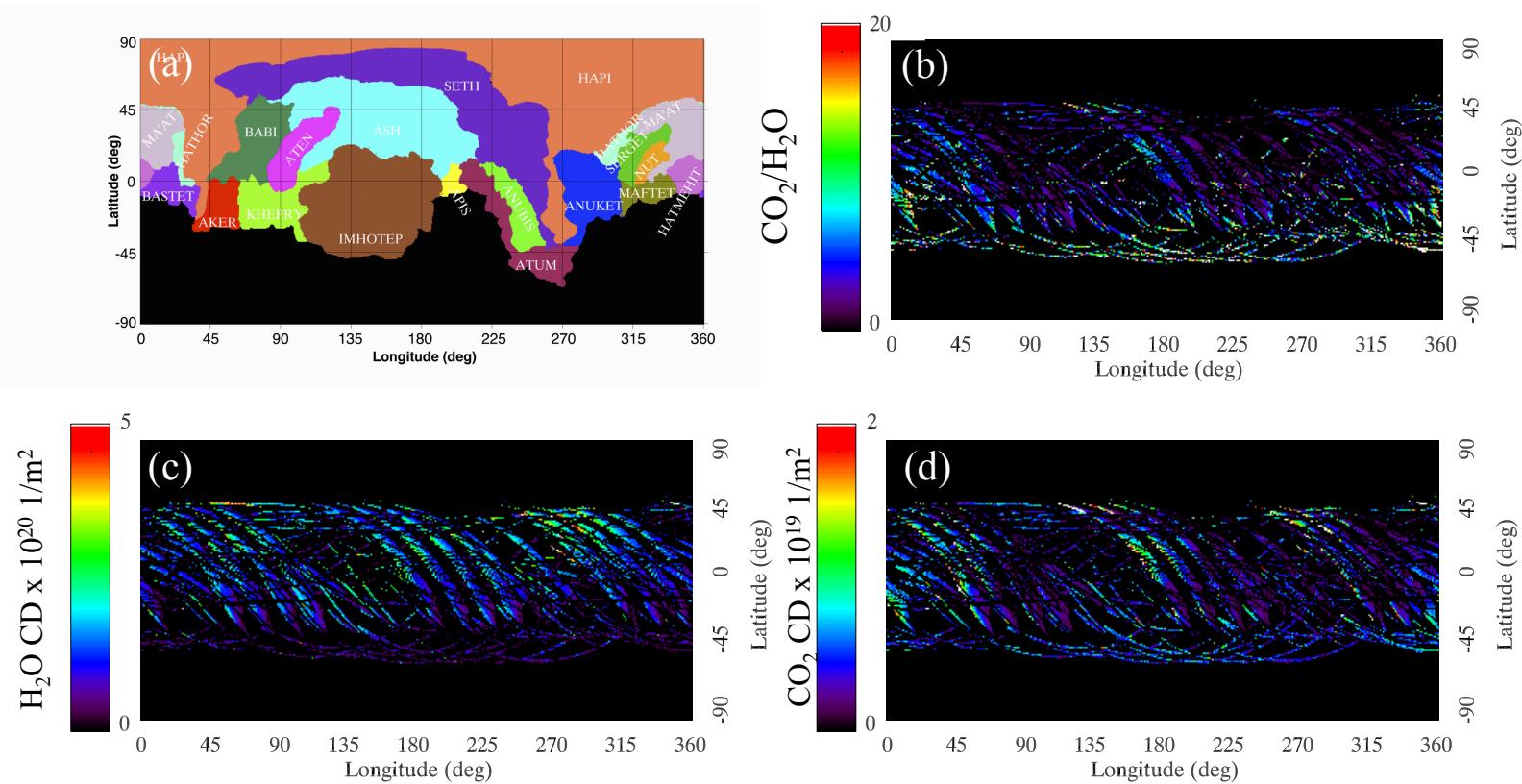

Fig. 10. a) Map of the comet's regions, identified on the surface as reported by Thomas et al. (2015). b) Cylindrical map of $\mathrm{CO}_{2}$ to $\mathrm{H}_{2} \mathrm{O}$ column density ratio, obtained using the data from the surface to $6 \mathrm{~km}$ from the nucleus. The values are provided as the percentage of the $\mathrm{CO}_{2}$ content with respect to the $\mathrm{H}_{2} \mathrm{O}$ one. Points having a $\mathrm{CO}_{2} / \mathrm{H}_{2} \mathrm{O}$ column density ratio exceeding the maximum value indicated by the colour ramp are marked in white. c) $\mathrm{H}_{2} \mathrm{O}$ column density map obtained considering the data at a tangent altitude in the range 0 to $6 \mathrm{~km}$ from the nucleus. d) The same as c), for $\mathrm{CO}_{2}$.

regions, a higher $\mathrm{CO}_{2}$ to $\mathrm{H}_{2} \mathrm{O}$ column density ratio could be explained either because of an excess of $\mathrm{CO}_{2}$ or because of a decrease in $\mathrm{H}_{2} \mathrm{O}$ emission due to a lower illumination. Two water ice deposits were identified on debris falls located in the Imhotep region on VIRTIS-M data in August 2014 (Filacchione et al. 2016). However, at the time of observations discussed in the present paper, this region was poorly illuminated, because it is in the comet's winter hemisphere; as a result, the higher $\mathrm{CO}_{2} / \mathrm{H}_{2} \mathrm{O}$ ratio could be due to a lower water emission.

Water and carbon dioxide contents were inferred from the ROSINA measurements in October 2014 at $3.15 \mathrm{AU}$ from the Sun, from which the $\mathrm{CO}_{2}$ to $\mathrm{H}_{2} \mathrm{O}$ ratio was derived (Le Roy et al. 2015). The authors reported a ratio variable from $2.5 \%$ to $80 \%$. These extreme values reflect the fairly large difference between the summer and winter hemispheres (Hässig et al. 2015). When the region of maximum solar illumination is considered, the ROSINA values of about $2.5 \%$, measured in the summer hemisphere, are similar to those derived using VIRTIS-H data covering the period from 24 November 2014 to 24 January 2015 (Bockelée-Morvan et al. 2015). The $\mathrm{CO}_{2}$ to $\mathrm{H}_{2} \mathrm{O}$ column density ratio obtained with VIRTIS-H data ranges between $2 \%$ and $7 \%$. Similarly, the parent molecules abundances were inferred from far-ultraviolet measurements of daughter species, such as $\mathrm{H}$ and $\mathrm{O}$ (Feldman et al. 2015). From these measurements, the reported $\mathrm{CO}_{2} / \mathrm{H}_{2} \mathrm{O}$ ratios during the period 22-23 October 2014 varied from $4.5 \%$ to $15 \%$.

Our measurements provide $\mathrm{CO}_{2} / \mathrm{H}_{2} \mathrm{O}$ estimations that are compatible with the lower values reported in the previous observations discussed above. VIRTIS-H reported $\mathrm{CO}_{2} / \mathrm{H}_{2} \mathrm{O}$ column density ratios equal to $4 \pm 0.8 \%$ above Aten region, $3.1 \pm 1.2 \%$ above Babi region, $3.2 \pm 1.7 \%$ over Seth, and $1.4 \pm 0.9 \%$ above the Hapi region (Bockelée-Morvan et al. 2015); VIRTIS-M values discussed here agree with those listed above, although calculated in a different period and for various values of heliocentric distance, solar illumination, and slant distance, making the comparison of limited validity. The highest ratio values $(\approx 20 \%)$ are observed in the southern regions and could be ascribed to a seasonal effect. The low solar illumination due to the winter season does not allow the water deposits located in the southern regions to be activated.

The southern regions, where $\mathrm{CO}_{2}$ appears to be locally more abundant, are less illuminated than those at the northern latitudes at the time of our observations. This could imply that we are measuring $\mathrm{CO}_{2}$ column density coming from a shallower layer of the southern regions, while a deeper $\mathrm{CO}_{2}$ deposit would require a higher thermal input to sublimate. The accessible diurnal skin depth is estimated to be of the order of $1 \mathrm{~cm}$ from MIRO measurements (Schloerb et al. 2015), and $\mathrm{CO}_{2}$ could be located below this layer.

We observe that $\mathrm{H}_{2} \mathrm{O}$ emission is highly variable, depending on the solar illumination and latitude, while $\mathrm{CO}_{2}$ content does not change as much in the summer or winter hemispheres, as shown in Fig. 5. In our observations, the carbon dioxide distribution increases towards the south-equatorial latitudes $\left(20^{\circ} \mathrm{S}-0^{\circ} \mathrm{S}\right)$, encompassing, among the others, the Imothep region. Indeed, the carbon dioxide source is likely to be located primarily in the southern hemisphere in a region not yet illuminated at the time of the observations presented in this work.

\section{Conclusions}

VIRTIS-M mapping capabilities allow us to trace the water and carbon dioxide distributions in the vicinity of the comet's nucleus. Water (and dust) emission shows two maxima located above Aten-Babi and Seth-Hapi areas in the "neck" region where the column density is higher than above the surrounding regions. This finding confirms that these two regions were the main sources of activity at the time of the VIRTIS-M observations in April 2015 when the comet was about $2 \mathrm{AU}$ distant 
from the Sun. Despite the uncertainty in connecting water emission with surface active areas, our results indicate a high water vapour outgassing occurring above the Hapi region, which is the same place as where the diurnal cycle of condensed water ice has been reported by De Sanctis et al. (2015). We have not seen any correlation between water vapour in the coma and the presence of exposed water ice deposits detected by VIRTIS-M on two debris falls at the base of elevated structures located in the Imhotep region (Filacchione et al. 2016). At the time of the observations analysed in this work, the Imhotep region was scarcely illuminated by the Sun, resulting in minimal water outgassing. On the other hand, we noticed that $\mathrm{CO}_{2}$ usually escapes from the nucleus southern hemisphere, producing a higher $\mathrm{CO}_{2}$ to $\mathrm{H}_{2} \mathrm{O}$ ratio.

On average, in the region corresponding to Imothep above the equatorial latitudes, the $\mathrm{CO}_{2} / \mathrm{H}_{2} \mathrm{O}$ column density ratio is $3.9 \pm 1.0 \%$, whereas values of $2.4 \pm 0.6 \%$ and $3.0 \pm 0.7 \%$ are measured above Aten-Babi and Seth-Hapi, respectively (Table 1). The decrease implies a higher water content in these two regions, while at the equatorial latitudes, water emission is not particularly evident because of the poor illumination. The subsurface layers of the southern hemisphere of the nucleus present an excess of $\mathrm{CO}_{2}$ compared to the equatorial and northern regions.

Acknowledgements. The authors would like to thank the following institutions and agencies that supported this work: Italian Space Agency (ASI - Italy), Centre National d'Études Spatiales (CNES - France), Deutsches Zentrum für Luftund Raumfahrt (DLR-Germany), National Aeronautic and Space Administration (NASA-USA). VIRTIS was built by a consortium from Italy, France, and Germany under the scientific responsibility of the Istituto di Astrofisica e Planetologia Spaziali of INAF, Rome (IT), which also leads the scientific operations. The VIRTIS instrument development for ESA has been funded and managed by ASI, with contributions from Observatoire de Meudon financed by CNES and from DLR. The instrument's industrial prime contractor was former Officine Galileo, now Selex ES (Finmeccanica Group) in Campi Bisenzio, Florence, IT. The authors wish to thank the Rosetta Science Ground Segment and the Rosetta Mission Operations Centre for their fantastic support throughout the early phases of the mission. The VIRTIS calibrated data will be available through ESA's Planetary Science Archive (PSA)Web site.

\section{References}

Acton, C. H. 1996, Planet. Space Sci., 44, 65

A'Hearn, M., Belton, M.J.S. Delamere, W., et al. 2011, Science, 332, 1396

Ammannito, E., Filacchione, G., Coradini, A., et al. 2006, Rev. Sci. Instrum., 77, 093109

Biver, N., Hofstadter, M., Gulkis, S., et al. 2015, A\&A, 583, A3

Bockelée-Morvan, D., Erard, S., Leyrat, C., et al. 2014, American Grophysical Union, Fall Meeting 2014, abstract P41C-3950

Bockelée-Morvan, D., Debout, V., Erard, S., et al. 2015, A\&A, 583, A6

Brownlee, D., Tsou, P., Aléon, J., et al. 2006, Science, 314, 1711

Capaccioni, F., Bockelée-Morvan, D., Filacchione, G., et al. 2015a, 46th Lunar and Planetary Science Conference, LPI Contribution, 1832, 2494

Capaccioni, F., Coradini, A., Filacchione, G., et al. 2015b, Science, 347, 0628

Ciarniello, M., Capaccioni, F., Filacchione, G., et al. 2015, A\&A, 583, A31

Combes, M., Moroz, V., Crovisier, J., et al. 1988, Icarus, 76, 404

Coradini, A., Capaccioni, F., Drossart, P., et al. 2007, Space Sci. Rev., 128, 529

Crovisier, J., \& Encrenaz, T. 1983, A\&A, 126, 170

De Sanctis, M., Capaccioni, F., Ciarniello, M., et al. 2015, Nature, 525, 500

Debout, V., Bockelée-Morvan, D., \& Zakharov, V. 2016, Icarus, 265, 110

Feaga, L., A'Hearn, M., Sunshine, J., et al. 2007, Icarus, 190, 345

Feldman, P. D., A'Hearn, M., Bertaux, J.-L., et al. 2015, A\&A, 583, A8

Filacchione, G. 2006, Calibrazioni a terra e prestazioni in volo di spettrometri ad immagine nel visibile e nel vicino infrarosso per l'esplorazione planetaria, Universitá degli Studi di Napoli Federico II, 316

Filacchione, G., Ammannito, E., Coradini, A., et al. 2006, Rev. Sci. Instrum., 77, 103

Filacchione, G., De Sanctis, M., Capaccioni, F., et al. 2016, Nature, 529, 368

Gersch, A., \& A'Hearn, M. 2014, ApJ, 787, 36

Gulkis, S., Allen, M., Von Allmen, P., et al. 2015, Science, 347, 0709

Hässig, M., Altwegg, K., Balsiger, H., et al. 2015, Science, 347, 0276

Jorda, L., Gaskell, G., Capanna, C., et al. 2016, Icarus, submitted

Le Roy, L., Altwegg, K., Belsiger, H., et al. 2015, A\&A, 583, A1

Lin, Z.-Y., Ip, W.-H., Lai, I.-L., et al. 2015, A\&A, 583, A11

Migliorini, A., Piccioni, G., Capaccioni, F., et al. 2013, Icarus, 226, 1115

Raponi, A. 2014, Spectrophotometric analysis of cometary nuclei from in situ observations, Universitá degli studi di Roma Tor Vergata

Reinhard, R. 1986, Nature, 321, 313

Sagdeev, R., Blamont, J., Galeev, A., et al. 1986, Nature, 321, 259

Schloerb, F., Kehim, S., von Allmen, P., et al. 2015, A\&A, 583, A29

Soderblom, L. A. Becker, T., Bennett, G., et al. 2002, Science, 296, 1087

Thomas, P., A'Hearn, M., Belton, M., et al. 2013, Icarus, 222, 453

Thomas, N., Sierks, H., Barbieri, C., et al. 2015, Science, 347, 0440

Villanueva, G., Mumma, M., Bonev, B., et al. 2012, J. Quant. Spectr. Radiat. Transf., 113, 202 
Appendix A

Table A.1. Summary of VIRTIS-M IR observations processed in this work.

\begin{tabular}{|c|c|c|c|c|c|c|c|c|c|c|}
\hline $\begin{array}{l}\text { Observation } \\
\text { name }\end{array}$ & $\begin{array}{c}\text { Start-end } \\
\text { time (UTC) }\end{array}$ & $\begin{array}{l}\text { Core } \\
\text { items }\end{array}$ & $\begin{array}{l}\text { Frame } \\
\text { timing }\end{array}$ & $\begin{array}{l}\text { SPC ALT } \\
(\mathrm{km})\end{array}$ & $\begin{array}{l}\text { Distance } \\
\mathrm{AU}\end{array}$ & $\begin{array}{c}\text { Phase } \\
\left({ }^{\circ}\right)\end{array}$ & $\begin{array}{l}\text { Subspc } \\
\text { LAT }\left(^{\circ}\right)\end{array}$ & $\begin{array}{c}\text { Subspc } \\
\text { LON }\left(^{\circ}\right)\end{array}$ & $\begin{array}{c}\text { SSOL } \\
\text { LON }\left({ }^{\circ}\right)\end{array}$ & $\begin{array}{c}\text { SSOL } \\
\text { LAT }\left(^{\circ}\right)\end{array}$ \\
\hline I1_00387140321 & 2015-04-08T18:59:56-19:23:12 & $432,64,70$ & $6,20,20$ & 136.3 & 1.90753 & 90.0 & -54.0 & 188.3 & 165.0 & 3.7 \\
\hline I1_00387141821 & 2015-04-08T19:24:56-19:48:12 & $432,64,70$ & $6,20,20$ & 136.2 & 1.90740 & 90.0 & -53.8 & 180.0 & 156.1 & 1.0 \\
\hline I1 00387146617 & 2015-04-08T20:44:52-21:12:52 & $432,256,168$ & $2,10,20$ & 135.8 & 1.90696 & 89.9 & -58.9 & 149.5 & 113.3 & 5.3 \\
\hline I1_00387154470 & 2015-04-08T22:55:45-23:19:01 & & & & & 89.9 & & & & 2 \\
\hline I1_00387155970 & 2015-04-08T23:20:45-23:44:01 & $432,64,70$ & & & 1.90614 & 89.9 & & & & 3.8 \\
\hline I1_00387251787 & 2015-04-10T01:57:42-02:14:58 & $432,64,52$ & $3,20,20$ & & 1.89765 & 89.8 & & & 347.2 & 3.5 \\
\hline I1_00387252927 & 2015-04-10T02:16:42-02:33:58 & $432,64,52$ & & & 1.89755 & 89.8 & & & & 3.7 \\
\hline I1_00387254067 & 2015-04-10T & 4. & & & 1.89745 & 89.8 & & & & 3.9 \\
\hline I1_00387 & $2015-$ & 432 & $1.5,2$ & & 84 & 89.8 & & & & 5.4 \\
\hline I1_00387263967 & 2015-04-10T05:20:42-05:45:58 & $432,64,76$ & $3,20,20$ & 133.5 & 1.89655 & 89.9 & -48.1 & 1866 & 227.8 & 4.6 \\
\hline I1_00387266007 & 2015-04-10T05 & 432,6 & 20 & 133.6 & 1.89637 & 89.9 & -47.5 & 175.5 & 1.2 & 4.0 \\
\hline I1_00387268047 & 2015-04-10T06:28:42-06:53:58 & $432,64,76$ & $3,20,20$ & 133.7 & 1.89619 & 89.9 & -48.4 & & 981 & 3.6 \\
\hline I1_00387284787 & $2015-04-1$ & $2,256,74$ & & & 1.89 & 89.9 & & 2.1 & 7.8 & 5.1 \\
\hline I1_00387 & 2015-04-1 & 6,74 & $1.5,10,20$ & & & & & & & 4.4 \\
\hline I1_00387 & 1 & & & & & & & & & 3.5 \\
\hline I1_0038 & 201 & & & & & 86.7 & & & & 3.4 \\
\hline I1_00387 & $2015-$ & & & & & 86.4 & & & & 4.1 \\
\hline I1_0038 & 2015 & & & & & 86.2 & .7 & & & 5.1 \\
\hline I1_00387 & 2015 & & & & & 86.1 & -2 & & & 1.7 \\
\hline I1_00387 & 2015-04-11 & 40 & & & 4 & & -3 & & & 3.2 \\
\hline I1_003874C & $-22: 16: 05$ & $432,256,140$ & 2,1 & & 1.88 & 85.2 & -3 & 7 & & 3.6 \\
\hline I1_00387413491 & 2015-04-11T22:52:46-23:16:06 & $432,256,140$ & 3,1 & & 1.8 & 84.9 & -2 & & 12 & 4.5 \\
\hline I1_00387416850 & 2015-04-11T23:48:45-12T00:12:05 & $432,256,140$ & 2,1 & 14 & 0 & 84 & -2 & 5 & 878 & 5.1 \\
\hline I1_00387422753 & 2015-04-12Т01:27:08-01:50:24 & $432,256,70$ & 5,2 & 142.1 & 1.88 & 84. & & & 8 & 3.7 \\
\hline I1_00387426413 & 2015-04-12T02:28:08-02:51:24 & $432,256,70$ & & & & & & & & 3.2 \\
\hline I1_00 & 24 & 0 & & & & 84.1 & & & & 3.3 \\
\hline I1_00387470597 & 2015-04-12T14:44:32-15:07:47 & $432,256,70$ & $1.5,20,20$ & 8 & 1.87824 & 81.9 & -23.9 & 32 & 9.9 & 3.2 \\
\hline I1_00387477791 & 2015-04-12T16:44:26-17:02:46 & $432,256,110$ & & 1465 & 1.87762 & 81.3 & -27.1 & 243.8 & 330.9 & 3.7 \\
\hline I1_00387481450 c & $2015-04-12 \mathrm{~T} 17: 45: 25-18: 03: 45$ & $432,256,110$ & 20 & & 1.87729 & 81.1 & & 210.8 & 298.8 & 4.6 \\
\hline I1_00387485051 d & 6 & 0 & & & & 81.0 & & & & 9 \\
\hline II_00387488650 f & 5 & 10 & & & & 80 & -18.7 & 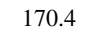 & . & 3.9 \\
\hline I1_003 & 201 & 0 & & & 9 & 80 & 2 & 1 & & 3.1 \\
\hline I1_00387497462 & 2015-04-12T22:12:17-22:35:32 & $2,256,70$ & $1.5,20,20$ & & 87 & 80.4 & -26.7 & 0 & 166 & 3.2 \\
\hline I1_00387501063 & $2015-04-12 \mathrm{~T} 23: 12: 18-23: 35: 34$ & $432,256,70$ & $3,20,20$ & & 1.87555 & 80 & -23.7 & $J 2 . J$ & & 3.9 \\
\hline I1_00387504662 & 2015-04-13Т00:12:17-13Т00:35:32 & $432,256,70$ & $1.5,20,20$ & & & 79.9 & -19.1 & & 107.0 & 4.8 \\
\hline I1_00387514012 & 2015-04-13Т02:48:08-03:11:27 & $432,256,140$ & $3,10,20$ & 150.0 & 1.87440 & 79.7 & -19.1 & 331.5 & 16.8 & 3.3 \\
\hline I1_00387517671 & 2015-04-13T03:49:06-04:12:26 & $432,256,140$ & $2,10,20$ & & 1.87408 & 79.5 & -23.3 & 299.9 & 357.5 & 3.1 \\
\hline I1_00387521272 & 2015-04-13Т04:49:07-05:12:27 & $432,256,140$ & $3,10,20$ & 151.0 & 1.87376 & 79.2 & -24.3 & 256.2 & 337.7 & 3.4 \\
\hline I1_00387524871 b & 2015-04-13T05:49:06-06:12:26 & $432,256,140$ & & & & 79.0 & -20.0 & 219.3 & 310.1 & 4.2 \\
\hline I1_00387531078 & 2015-04-13Т07:32:33-07:55:49 & 43225670 & & & 1.87289 & 78.8 & -15.7 & 181.3 & 237.5 & 4.4 \\
\hline I1_00387534739 & 015.04 12T08.22.24 08.56 .50 & 25670 & & & 57 & 78.8 & - & 1 & 7 & 3.5 \\
\hline I1_00 & $150,0>0$ & 70 & & 15 & & 78. & -19.7 & 136.2 & 186.0 & 3.1 \\
\hline I1_00 & $2015-$ & 0 & ? & 15 & & 78 & 0 & 070 & 16 & 32 \\
\hline I1_00. & 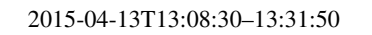 & 432,2 & & - & 11 & 77 & -15.2 & 12 & 830 & 48 \\
\hline I1_00387554894 h & 2015-04-13T14:09:29-14:32:49 & $432,256,140$ & $2,10,20$ & 154.8 & 1.87078 & 77.9 & -14.6 & 353.7 & 43.3 & 4.0 \\
\hline I1_00387558495 i & 2015-04-13T15:09:30-15:32:50 & $432,256,140$ & $3,10,20$ & 155.4 & 1.87047 & 77.8 & -16.2 & 332.8 & 17.9 & 3.3 \\
\hline I1_00387561494 & 2015-04-13T15:59:29-16:22:49 & $432,256,140$ & $2,10,20$ & & 1.87020 & 77 & -19.2 & & 1.8 & 3.0 \\
\hline I1_00387572309 & 2015-04-13T18:59:44-19:34:00 & $432,64,103$ & $5,20,20$ & 157.3 & 1.86922 & 77.0 & -14.5 & 198.1 & 274.9 & 4.8 \\
\hline I1_00387574469 & 2015-04-13T19:35:44-20:10:00 & $432,64,103$ & $5,20,20$ & 157.5 & 1.86902 & 77.0 & -13.6 & 186.2 & 248.0 & 4.6 \\
\hline I1_00387576629 & 2015-04-13Т20:11:44-20:46:00 & $432,64,103$ & $5,20,20$ & 157.8 & 1.86883 & 77.0 & -13.5 & 175.1 & 225.7 & 4.0 \\
\hline I1_00387578789 & 2015-04-13Т20:47:44-21:22:00 & $432,64,103$ & $5,20,20$ & 158.2 & 1.86864 & 76.9 & -14.1 & 163.4 & 208.7 & 3.5 \\
\hline I1_00387587938 & 2015-04-13T23:20:13-23:54:29 & $32,64,103$ & & & 1.86783 & 76.4 & -19.5 & 76.3 & 157.8 & 3.3 \\
\hline I1_00387590098 & $015-04-13 \mathrm{~T} 23: 56: 13-14 \mathrm{~T} 00: 30: 29$ & & & & & 76.3 & & 52.3 & 142.7 & 3.8 \\
\hline
\end{tabular}

Notes. Core items values indicate cube size in bands, sample, and lines. Frame timing values correspond to the exposure duration (s), repetition time between two consecutive lines (s), and dark current acquisition rate. Distance is the heliocentric distance in AU, as reported in the geometric files associated to each image. Observation names in italics indicate images displayed in Figs. 6 and 7, and the letters in bold identify their position in the sequence. 